\title{
Preoperative factors predicting conversion from laparoscopic to open cholecystectomy
}

\author{
Mohammad A Gad, MD; Mohamed E Shams, MD; Gouda M Ellabban, MD
}

Department of Surgery, Suez Canal University, Ismailia, Egypt.

\begin{abstract}
Background: Laparoscopic cholecystectomy (LC) has replaced open cholecystectomy (OC) for the treatment of gallbladder disease. However, certain cases still require conversion to open procedures. Conversion to OC can be predicted based on parameters available preoperatively. This study identified risk factors that may predict conversion from a laparoscopic to an open procedure.

Patients and methods: From January 2007 to January 2010, a total of 130 laparoscopic cholecystectomies performed in our list were included in this prospective clinical study at Suez Canal University Hospitals. Patients were mostly females (71.5\%) and age ranged from 23ys$69 y$ with symptomatic GB stone disease. Analysis of many predictive parameters including; history, laboratory data, ultrasound results, and intraoperative details were performed. Multivariate logistic regression was used to determine those variables predicting conversion of LC to open OC during the procedure.

Results: Laparoscopic cholecystectomy was converted into OC in $12.3 \%$ of the patients. The cause of conversion in this group was uncontrollable bleeding from injured cystic artery during difficult dissection in (37.5\%), marked adhesions due to previous upper abdominal surgery (31.3\%), inflamed thick GB wall (18.7\%) and marked obesity (12.5\%). Preoperative factors that can predict conversion from laparoscopic to OC are (in descending sort) elevated total leucocytic count (TLC) and fever(acute inflammation), pericholecystic fluid collection by US, elevated bilirubin, BMI $>35 \mathrm{Kg} / \mathrm{m}^{2}$, thickened GB wall, US positive Murphy's sign, previous upper abdominal surgery, low albumin, age $>60 y e a r s$ and ascites.

Conclusion: In feverish morbidly obese patients with elevated TLC, thickened GB wall and/or pericholecystic fluid collection on US assessment with or without previous upper abdominal surgery, or low plasma albumin or mild jaundice (patients with one or more predictive factors), these patients should be subjected to LC by highly expert skillful team or may be the option of open cholecystectomy is the preferable from the start to lessen morbidity.

Key words: Laparoscopic cholecystectomy; predictive factors; conversion.
\end{abstract}

\section{Introduction:}

Gallbladder disease is the most common of all digestive disorders requiring hospitalization, and cholecystectomy is the most common elective abdominal operation undertaken. ${ }^{1}$ Today, cholecystectomy is the safest, the most effective and widely recommended treatment for gallstone disease. Since the introduction of laparoscopic cholecystectomy into general practice in 1990, it has rapidly become the gold standard for symptomatic cholelithiasis, while open cholecystectomy is now reserved for difficult and problematic cases. ${ }^{2}$

Laparoscopic cholecystectomy decreases postoperative pain, allows earlier oral intake, shortens hospital stay, enhances earlier return to normal activity and improves cosmoses over open cholecystectomy. ${ }^{3}$ Day after day it has been considered for the management of more complicated gallbladder diseases. ${ }^{4}$ With increasing laparoscopic experience, there are few contraindications to laparoscopic cholecystectomy for symptomatic cholelithiasis. However, approximately $2 \%$ to 
$15 \%$ of patients require conversion to open cholecystectomy for various reasons. ${ }^{5}$

Accurate prediction of the risk of conversion is of great interest to the clinician as patients with a high risk of conversion could be operated on either by or under the supervision of a more experienced surgeon. When there is high predicted risk of conversion, this may allow the surgeon to take an early decision to convert to open cholecystectomy when difficulty is encountered during dissection; this may shorten the duration of surgery and decrease the associated morbidity. ${ }^{4-6}$ The aim of the current study was to evaluate the preoperative factors (clinical, laboratory and ultrasonographic) predicting conversion from laparoscopic cholecystectomy to open cholecystectomy.

\section{Patients and methods:}

This prospective clinical trial included a total of 130 patients; mostly females $(71.5 \%)$ and age ranged from $23 y s-69 y s$ with symptomatic GB stone disease who were admitted to our list and surgery department along 3 years duration (from January 2007 January 2010). Other number of cholecystectomies in the same period was excluded because it underwent $\mathrm{OC}$ from the start (acutely inflamed or technical problems). Patients were evaluated via clinical, laboratory and US assessment. All the patients of our study underwent either LC or OC. Rate and causes of conversion were estimated.

\section{Results:}

In this study, the mean age of our patients was 45.9 years. More than two thirds of the patients were females $(71.5 \%)$. Less than half of the patients were from rural areas $(41.5 \%)$. It was found that $20 \%$ of the studied patients were smokers.

The most common clinical presentation was right hypochondrial pain and/or epigastric pain (73.8\%). Nausea with or without vomiting was evident among $36.2 \%$. Fatty dyspepsia was present among more than two thirds of the patients $(68.5 \%)$. The least common presentations were fever $(14.6 \%)$ and history of jaundice (13.1\%). Temperature was more than $37.5^{\circ} \mathrm{C}$ in 19 patients. Murphy's sign was evident among $22.3 \%$ of the patients and ascites was clinically present in $10.8 \%$ of the studied patients.

Total bilirubin was sub-clinically elevated or ting of jaundice in $16.1 \%$ of the cases while TLC was elevated in $21.5 \%$ of the patients. Liver enzymes were elevated in $18.5 \%$ of the patients while plasma albumin was reduced in $13.1 \%$.

The most common US finding was the thickened GB wall (28.5\%). Ultrasonographic Murphy's sign was elicited among $23.8 \%$ of the studied patients. The GB was visualized to be distended in $17.7 \%$ of the studied patients and pericholecystic fluid collection was evident in $14.6 \%$ of the cases.

Laparoscopic cholecystectomy was converted to OC in 16 patients $(12.3 \%)$. The cause of conversion in the largest group of these cases was uncontrollable bleeding from injured cystic artery (37.5\%) during dissection. Noticeable adhesions due to previous upper abdominal operations were the cause of conversion in $31.3 \%$ of this group while marked obesity was the cause of conversion in $12.5 \%$ of the converted patients.

Table (1): Comparison of surgery duration and hospital stay among converted and laparoscopic patients $(n=130)$.

\begin{tabular}{|l|c|c|c|}
\hline & Converted & Laparoscopic & p-value \\
\hline Duration of surgery (minutes) & $135.9 \pm 8.1$ & $86.3 \pm 23.1$ & $0.001^{*}$ \\
\hline Hospital stay (days) & $3.2 \pm 0.3$ & $1.4 \pm 0.9$ & $0.001^{*}$ \\
\hline
\end{tabular}

P-value 0.001 
There was statistically significant difference between patients who were converted to OC as regarding; age, BMI, previous upper abdominal operation, fever, elevated TLC, mild elevated bilirubin, +US Murphy's sign, thickened GB wall and pericholecystic oedema. Sex, smoking habit, elevated alkaline phosphatase and liver enzymes and US diagnosed ascites didn't show any statistically significant difference Table(2).

Table (2): Comparison between laparoscopic cases and converted cases among the studied patients.

\begin{tabular}{|l|c|c|c|c|}
\hline & & $\begin{array}{c}\text { Converted } \\
(\mathrm{n}=16)\end{array}$ & $\begin{array}{c}\text { Laparoscopic } \\
(\mathrm{n}=114)\end{array}$ & $\mathrm{p}$-value \\
\hline Male & $\mathrm{N}(\%)$ & $5(31.3 \%)$ & $32(28.1 \%)$ & $0.9(\mathrm{NS})$ \\
\hline Age & Mean $\pm \mathrm{SD}$ & $59.1 \pm 6.1$ & $40.9 \pm 5.3$ & $0.001^{*}$ \\
\hline BMI & Mean $\pm \mathrm{SD}$ & $36.2 \pm 3.5$ & $28.5 \pm 5.4$ & $0.001^{*}$ \\
\hline Previous upper abdominal surgery & $\mathrm{N}(\%)$ & $5(31.3 \%)$ & $11(9.6 \%)$ & $0.001^{*}$ \\
\hline Smoker & $\mathrm{N}(\%)$ & $3(18.8 \%)$ & $23(20.2 \%)$ & $0.8(\mathrm{NS})$ \\
\hline Fever & $\mathrm{N}(\%)$ & $6(37.5 \%)$ & $13(11.4 \%)$ & $0.02 *$ \\
\hline Clinically evident ascites & $\mathrm{N}(\%)$ & $2(12.5 \%)$ & $12(10.5 \%)$ & $0.8(\mathrm{NS})$ \\
\hline History of jaundice & $\mathrm{N}(\%)$ & $3(18.8 \%)$ & $14(12.3 \%)$ & $0.7(\mathrm{NS})$ \\
\hline Elevated WBC count & $\mathrm{N}(\%)$ & $8(50 \%)$ & $20(17.5 \%)$ & $0.01 *$ \\
\hline Elevated T. bilirubin(subclinical) & $\mathrm{N}(\%)$ & $6(37.5 \%)$ & $15(13.2 \%)$ & $0.04 *$ \\
\hline Low albumin & $\mathrm{N}(\%)$ & $3(18.8 \%)$ & $14(12.3 \%)$ & $0.7(\mathrm{NS})$ \\
\hline Elevated alkaline phosphatase & $\mathrm{N}(\%)$ & $2(12.5 \%)$ & $11(9.6 \%)$ & $0.9(\mathrm{NS})$ \\
\hline Elevated liver enzymes & $\mathrm{N}(\%)$ & $3(18.8 \%)$ & $21(18.4 \%)$ & $0.7(\mathrm{NS})$ \\
\hline Thickened gall bladder wall by U/S & $\mathrm{N}(\%)$ & $8(50 \%)$ & $29(25.4 \%)$ & $0.08(\mathrm{NS})$ \\
\hline Pericholecystic fluid collection & $\mathrm{N}(\%)$ & $6(37.5 \%)$ & $13(11.4 \%)$ & $0.02 *$ \\
\hline Ultrasonographic Murphy's signs(+) & $\mathrm{N}(\%)$ & $7(43.8 \%)$ & $24(21.1 \%)$ & $0.09(\mathrm{NS})$ \\
\hline Clinical and ultrasonographic ascites & $\mathrm{N}(\%)$ & $2(12.5 \%)$ & $15(13.2 \%)$ & $0.8(\mathrm{NS})$ \\
\hline
\end{tabular}

*Statistically significant at 0.05 level.

**Statistically significant at 0.01 level.

$N S$ : NO statistically significant difference ( $p$-value $>0.05)$.

Multivariate analysis of preoperative patient's factors that independently predict conversion from LC to OC showed that $28.6 \%$ of the morbid obese patients ( 2 out 7 cases) have been subjected to conversion (OR: 3.1, CI: $0.6-17.8)$ and $16.7 \%$ of the patients older than 60 years old have been converted (OR: $1.5 \mathrm{CI}: 0.3$ - 5.9) .

Multivariate analysis of preoperative symptoms and signs that independently predict conversion showed that $31.6 \%$ of the patients with fever have been converted to OC (OR: 4.7, CI: $1.5-15.09$ ) and $31.3 \%$ of the patients with history of previous upper abdominal surgery have been subjected to conversion (OR: 2.55 , CI: 1.21 - 15.41) while $14.3 \%$ of the patients with ascites (clinically) have been converted (OR:1.2,CI: 0.2 - 6.1).

Multivariate analysis of preoperative laboratory findings that were independently 
predictive of conversion from LC to OC showed that $28.6 \%$ of the patients with elevated TLC have been converted from laparoscopic to OC (OR: $4.8, \mathrm{CI}: 1.6-14.2$ ), $28.6 \%$ of the patients having mild elevated total bilirubin have been converted to OC (OR: 4, CI: 1.3 12.6) and $17.6 \%$ of the patients with low albumin have been subjected to conversion (OR: 1.6, CI: $0.4-6.6$ ).

Table(3): Multivariate analysis of preoperative ultrasonographic factors that independently predict conversion from $\mathrm{LC}$ to $\mathrm{OC}$.

\begin{tabular}{|l|c|c|c|c|c|}
\hline & $\begin{array}{c}\text { Total } \\
\text { number }\end{array}$ & $\begin{array}{c}\text { Conversion } \\
(\mathbf{n}, \%)\end{array}$ & $\begin{array}{c}\text { Odds } \\
\text { ratio }\end{array}$ & $\mathbf{9 5 \%}$ CI & p-value \\
\hline $\begin{array}{l}\text { Pericholecystic fluid } \\
\text { collection by U/S }\end{array}$ & 19 & $6(31.6 \%)$ & 4.7 & $1.5-15.1$ & $0.001^{*}$ \\
\hline $\begin{array}{l}\text { Ultrasonographic } \\
\text { Murphy's signs(+) }\end{array}$ & 31 & $7(22.6 \%)$ & 2.9 & $0.9-8.7$ & $0.001^{*}$ \\
\hline $\begin{array}{l}\text { Thickened gall bladder } \\
\text { wall by U/S }\end{array}$ & 37 & $8(21.6 \%)$ & 2.9 & $1.1-8.6$ & $0.001^{*}$ \\
\hline Ascites & 17 & $2(11.8 \%)$ & 0.9 & $0.1-4.6$ & $0.6(\mathrm{NS})$ \\
\hline
\end{tabular}

*Statistically significant (p-value $<0.05)$.

CI: confidence interval.

Table (4): Multivariate analysis of preoperative factors that independently predict conversion.

\begin{tabular}{|l|c|c|c|c|c|}
\hline & $\begin{array}{c}\text { Total } \\
\text { number }\end{array}$ & $\begin{array}{c}\text { Conversion } \\
(\mathbf{n}, \mathbf{\%})\end{array}$ & $\begin{array}{l}\text { Odds } \\
\text { ratio }\end{array}$ & $\mathbf{9 5 \%}$ CI & p-value \\
\hline Elevated WBC & 28 & $8(28.6 \%)$ & 4.8 & $1.6-14.2$ & $0.03^{*}$ \\
\hline Fever & 19 & $6(31.6 \%)$ & 4.7 & $1.5-15.09$ & $0.001^{*}$ \\
\hline Pericholecystic fluid collection by U/S & 19 & $6(31.6 \%)$ & 4.7 & $1.5-15.1$ & $0.001^{*}$ \\
\hline Elevated total bilirubin(mild) & 21 & $6(28.6 \%)$ & 4 & $1.3-12.6$ & $0.001^{*}$ \\
\hline Morbid obesity (BMI > 35 Kg/m2) & 7 & $2(28.6 \%)$ & 3.1 & $0.6-17.8$ & $0.001^{*}$ \\
\hline Thickened gall bladder wall by U/S & 37 & $8(21.6 \%)$ & 2.9 & $1.1-8.6$ & $0.001^{*}$ \\
\hline Ultrasonographic Murphy's signs(+) & 31 & $7(22.6 \%)$ & 2.9 & $0.9-8.7$ & $0.001^{*}$ \\
\hline Previous upper abdominal surgery & 16 & $5(31.3 \%)$ & 2.55 & $1.21-15.41$ & $0.001^{*}$ \\
\hline Low albumin & 17 & $3(17.6 \%)$ & 1.6 & $0.4-6.6$ & $0.4(\mathrm{NS})$ \\
\hline Older age (Age $>\mathbf{6 0})$ & 18 & $3(16.7 \%)$ & 1.5 & $0.3-5.9$ & $0.01^{*}$ \\
\hline Ascites & 17 & $2(11.8 \%)$ & 0.9 & $0.1-4.6$ & $0.6(\mathrm{NS})$ \\
\hline
\end{tabular}

*Statistically significant ( $p$-value $<0.05$ ).

CI: confidence interval. 


\section{Discussion:}

The current study was conducted to evaluate the preoperative factors (clinical, laboratory and ultrasonographic) predicting conversion from LC to OC. In our study the overall conversion rate from $\mathrm{LC}$ to $\mathrm{OC}$ was estimated to be $12.3 \%$. In previous studies, conversions to $\mathrm{OC}$ were $8.1 \%$ and $5.3 \% .7,8$ This estimated rate of conversion is less compared to our rate $(12.3 \%)$ and may be due to the large series in these studies. Similarly; Lo et al., ${ }^{9}$ demonstrated a conversion rate of $11 \%$ that is nearly consistent with our findings. However, approximately $2 \%$ to $15 \%$ of patients require conversion to open surgery for various reasons. ${ }^{5,6}$ Conversion to $\mathrm{OC}$ is occasionally necessary to avoid or repair injury, delineate confusing anatomic relationships, or treat associated conditions. Conversion to $\mathrm{OC}$ has been associated with increased overall morbidity, surgical site and pulmonary infections, and longer hospital stays ${ }^{10}$ and this finding came in agreement with our data as the mean operative time and duration of hospital stay were significantly prolonged with conversion.

The ability to accurately identify an individual patient's risk for conversion based on preoperative information can result in more meaningful and accurate preoperative counseling. Stratification of risk for technical difficulty, may improve patient safety by minimizing time to conversion, and helps to identify patients in whom a planned open cholecystectomy is indicated. ${ }^{11,12}$

Recent results demonstrated that conversion to $\mathrm{OC}$ can be predicted based on parameters available preoperatively. ${ }^{7}$ Accordingly we have found that body temperature more than $37.5^{\circ} \mathrm{C}$ was associated with conversion rate $31.6 \%$ (6 out of 19 cases).

In this study the first (commonest) cause of conversion was uncontrollable bleeding from injured cystic artery during dissection in difficult situations (37.5\%). Marked adhesions that make visualization via laparoscope very difficult was the second common cause of conversion in $31.3 \%$ of the patients with previous upper abdominal surgery. The thickened GB wall with pericholecystic oedema with unclear anatomy and difficult dissection was the cause of conversion in $18.7 \%$ of the cases. Among 12.5\% of the patients, marked obesity was the cause of conversion in the converted group (total 16 patients). Conversion was significantly higher in our patients with fever $>37.5^{\circ} \mathrm{C}$, elevated WBC, mild elevated bilirubin and low albumin. Kanaan and coworkers ${ }^{13}$ found that patients having open conversion were significantly older, had greater prevalence of cardiovascular disease and were more likely to be males. This is not in agreement with our results. Conversion in acute cholecystitis patients was associated with a greater leukocyte count; in gangrenous cholecystitis patients, $29 \%$ had open conversion. ${ }^{13}$

Among different ultrasonographic findings, thickened gall bladder wall, pericholecystic fluid collection and positive US Murphy's sign were significantly more prevalent with converted patients. Sex, smoking habit, elevated alkaline phosphatase and liver enzymes didn't show any statistically significant difference. Rosen et al., ${ }^{8}$ retrospectively evaluated 34 parameters including patient demographics, clinical history, laboratory data and ultrasound results among a total of 1347 laparoscopic cholecystectomies performed at the Cleveland Clinic Foundation (CCF) to assess preoperative factors predicting conversion from LC to OC. Multivariate analysis revealed that for all cases, a white blood cell count $>9$ (2.9 greater odds ratio $[\mathrm{OR}]$ of conversion $\mathrm{P}=0.006$ ) and $\mathrm{a}$ gallbladder wall thickness $>0.4 \mathrm{~cm}(7.2 \mathrm{OR}$, $\mathrm{P}<0.001)$ predicted conversion to OC. These results are in agreement with our findings, in addition, obese patients with acute cholecystitis undergoing $\mathrm{LC}$ have an increased chance of conversion like our results. ${ }^{8}$

Multivariate analysis of the preoperative factors that can predict conversion from LC to $\mathrm{OC}$ showed that elevated $\mathrm{WBC}$, fever, pericholecystic fluid collection, thickened GB wall and positive Murphy's sign, elevated bilirubin, BMI $>35 \mathrm{Kg} / \mathrm{m}^{2}$, previous upper abdominal surgery, low plasma albumin, older age $>60$ years old, and ascites are significant factors that can independently predict conversion from $\mathrm{LC}$ to $\mathrm{OC}$.

Other researchers examined risk factors predicting conversion in an elective 
cholecystectomy. These authors found that in elective LC for elderly patients (65 years or older), males, and patients with multiple attacks (more than 10) of biliary colic, or a documented history of acute cholecystitis were more likely to require conversion. ${ }^{14}$

In similar study performed the conversion group had significantly more elderly $(\sim 65$ years) patients $(66 \%$ vs. $37 \%$; $\mathrm{P}=0.02)$ and larger gallstones as shown on US ( $25 \mathrm{~mm}$ vs. $15.5 \mathrm{~mm} ; \mathrm{P}=0.03)$. Other preoperative factors associated with severe inflammation were not predictive. They concluded that conversion from LC to OC for acute cholecystitis is at risk for postoperative complications. In elderly patients with large gallstones, the surgeon should make an early decision to convert if severe adhesions are encountered. ${ }^{9,15}$

Consistent with our results, Liu et al., ${ }^{15}$ found that age more than 65 years, obesity, interval elective LC for acute cholecystitis, and a thickened gallbladder wall predicted conversion. Some authors noted a higher incidence of conversion in male patients. 5,6,16,17 This finding wasn't obvious in our study.

Another multivariate analysis identified male gender, elevated white blood cell count, low serum albumin, ultrasound finding of pericholecystic fluid, and elevated total bilirubin as independent predictors of conversion. ${ }^{7}$ This is consistent with our findings but for that we have identified gender not to be a predictive factor.

In previous studies, it was estimated that conversion prolongs postoperative hospital stay as long as 9.7 days. ${ }^{18-20} \mathrm{We}$ have also realized that conversion significantly prolongs the duration of hospital stay. These results are also consistent with what has been reported by other investigators. ${ }^{21}$

In conclusion we can state that older age patients age $>60$ years old or morbidly obese with fever, elevated TLC, thickened GB wall and/pericholecystic fluid collection on US assessment or low plasma albumin should be subjected to open cholecystectomy from the start or be done by laparoscopy under supervision of highly expert team with the option of conversion in mind to avoid unneeded post-operative complications.

\section{References:}

1- Salky BA, Edye MB: The difficult cholecystectomy; problems related to concomitant diseases. Semin Laparosc Surg 2003; 5 (2): 107-114.

2- Robert E, Michael Cho, Mathew M: The spectrum and cost of complicated gallstone disease in California. Arch Surg 2000; 1021-1025.

3- Hollington P, Toogood GJ, Padbury RT: A prospective randomized trial of day-stay only versus overnight-stay laparoscopic cholecystectomy. Aust NZ J Surg 1999; 69: 841-843.

4- Neri V, Ambrosi D, Di Lauro G, Fersini A: Difficult cholecystectomies: Validity of the laparoscopic approach. JSLS 2003; 7: 329-333.

5- Kama Na, Kologlu M, Doganay M, Reis E, Atli M, Dolapci M: A risk score for conversion from laparoscopic to open cholecystectomy. Am J Surg 2001; 181: 520-525.

6- Kama Nb, Doganay M, Dolapci M, et al: Risk factors resulting in conversion of laparoscopic cholecystectomy to open surgery. Surg Endosc 2001;15: 965-968.

7- Lipman JM, Claridge JA, Haridas M, Martin $\mathrm{M}$, et al: Preoperative findings predict conversion from laparoscopic to open cholecystectomy. Surgery 2007; 142: 556565.

8- Rosen M, Brody F, Ponsky J: Predictive factors for of conversion laparoscopic cholecystectomy. Am J Surg 2002; 184: 254-258.

9- Lo CM, Fan ST, Liu CL, Lai ES, Wong J: Early decision for conversion of laparoscopic to open cholecystectomy for treatment of acute cholecystitis. Am J Surg 1997; 173: 513-517.

10-Livingston E, Rege R: A nationwide study of conversion from laparoscopic to open cholecystectomy. Am J Surg 2004; 188 : 205-211.

11-Bulbuller N, Ilhan Y, Baktir A, Kirkil C, Dogru O: Implementation of a scoring system for assessing difficult cholecystectomies in a single center. Surg Today 2006; 36: 37-40. 
12-Tang B, Cuschieri A: Conversions during laparoscopic cholecystectomy: Risk factors and effects on patient outcome. $J$ Gastrointest Surg 2006; (7): 1081.

13-Kanaan SA, Murayama KM, Merriam LT, Dawes LG, Prystowsky JB, Rege RV: Risk factors for conversion of laparoscopic to open cholecystectomy. J Surg Res 2002; 106: 20-24.

14-Sanabria JR, Gallinger S, Croxford, R, et al: Risk factors in elective laparoscopic cholecystectomy for conversion to open cholecystectomy. J Am Coll Surg 1995; 179: 696-704.

15-Liu CL, Fan ST, Lai EC, et al: Factors affecting conversion of laparoscopic cholecystectomy to open surgery. Arch Surg 1996; 131: 98-101.

16-Fried GM, Barkun JS, Sigman HH, Joseph L, Clas D, Garzon J, Hinchey EJ, Meakins JL: Factors determining conversion to laparotomy in patients undergoing laparoscopic cholecystectomy. Am J Surg 1994; 167: 35-39.
17-Hutchinson $\mathrm{CH}$, Traverso LW, Lee FT: Laparoscopic cholecystectomy. Do preoperative factors predict the need to convert to open? Surg Endosc 1994; 8: 875-880.

18-Schäfer M, Krähenbühl L, Büchler MW: Predictive factors for the type of surgery in acute cholecystitis. Am J Surg 2001; 182: 291-297.

19-Schirmer BD, Edge SB, Dix J, et al: Laparoscopic cholecystectomy: Treatment of choice for symptomatic cholelithiasis. Ann Surg 1991; 213: 665-677.

20-Rattner DW, Ferguson C, Warshaw AL: Factors associated with successful laparoscopic cholecystectomy for acute cholecystitis. Ann Surg 1993; 217: 233236.

21-Jones K, DeCamp S, Mangram AJ, Dunn EL: Laparoscopic converted to open cholecystectomy minimally prolongs hospitalization. The American Journal of Surgery 2005; 190: 888-890. 